\title{
Solutions to the Coming Crisis in Social Security: Save Today or Work Tomorrow?
}

\author{
by Denis Kessler*
}

\section{Introduction}

The future of old age insurance schemes is causing increasingly marked concern. A growing number of observers are asking about the future viability of pension and social security schemes. A growing number of studies have explored the adverse effects that these schemes may have on savings and capital accumulation, on work effort and even on fertility.

These questions and studies have not been superfluous. We now have a better understanding of the reasons underlying the creation and development of old age security schemes (Kessler, 1989). We can now better assess the possible futures of old age security schemes in industrialized countries. We are indeed facing certain trade-offs, and the way we will work and age tomorrow depends largely on the individual and collective choices that are made today, implicitly or explicitly.

The basic reason for which social security schemes operating transfers between the different age groups - and hence between successive cohorts - will be put under heavy pressure is linked, as is well known, to the historical decline in the fertility rate ("the baby bust") that followed twenty years of high fertility ("the baby boom") and which took place in all industrialized nations. This dramatic change in the fertility rate is still largely an open question and this is partially why assessing the future of fertility patterns is not an easy task (Part 1). The consequent change in the age structure of the population in the future will affect all intergenerational transfer mechanisms, such as social security and health insurance (Part 2). To avoid the potential disruptions that the aging of populations can generate, an increase of the savings rate has been advocated so as to accumulate funds to ease the burden that aging will put on tomorrow's contributors and/or taxpayers. Is this an efficient solution, and if so, how can the savings rate be raised, in the knowledge that it has been declining or stable in all industrialized countries since the mid seventies (Part 3)? Extending the duration of an individual's working life, in other words decreasing the average length of retirement, is also presented as a positive solution to the social security dilemma. This would raise the number of contributors and decrease the number of pensioners, and avoid an unsustainable increase of the contribution rate or of tax levels. Questions may also be raised about the efficiency and the feasibility of this solution, taking into account the historical decline in the activity rates of aged workers (Part 4$)$ ?

* Ecole des Hautes Etudes en Sciences Sociales and Geneva Association.

The author wishes to thank Rachel Meghir and Carlos Pardo for their comments on the draft of this paper. 


\section{Is the decline in fertility irreversible?}

We know that transfer schemes, especially when they operate according to the pay-asyou-go principle, will face difficulties in the years to come due to the aging of the population resulting from a sharp decline in fertility rates in the 1960s and 1970s (Graph 1).

Almost all European countries, not to say almost all industrialized nations, have experienced a slowing down of their population growth. This phenomenon will, of course, affect all those systems operating as a pure transfer mechanism from the young to the aged, even if the fertility rate were to bounce back in the near future. The children that were not born during the last 20 years will never be replaced. Age "pyramids" twenty or thirty years from now will present some strange patterns, corresponding to the sequence of a high and then a low fertility rate.

Let us introduce here our first argument: the decline in fertility rates that started twenty years ago is as difficult to explain as the sharp rise in the fertility rates that occurred just at the end of World War Two. Why did the baby boom turn into a baby bust? Some have argued the idea that fertility is a cyclical phenomenon, as are economic phenomena. In certain respects, demographic and economic cycles could be linked, but they would neither be synchronous nor of the same amplitude. In a less fashionable approach, certain observers have just proposed the idea that a large cohort gives birth to a small cohort (for some obscure reasons), itself giving birth to a large cohort, and so on.

These cyclical approaches to fertility may be appropriate to United States history but quite irrelevant for many European countries, that have experienced what is now called the "demographic transition", and seem to be experiencing a long-term trend of declining fertility (even though there may be historically limited departures from the trend). Let us remark that most projections of populations seem to have adopted this latter hypothesis, since they rest on assumptions of constant fertility rates (even if a set of alternate fertility rates is generally presented). Fertility rates are indeed difficult to predict since we have little explanation for their past development.

Furthermore, there is a growing consensus among experts that it is impossible to act on the fertility rate. Indeed, most studies on fertility do not seem very conclusive on those key factors likely to contribute positively to the rate of growth of the population. A population policy - if needed - is by any standards more difficult to define than an economic policy - if needed.

Of course, a population pattern can be reshaped through migration flows. But for both economic reasons (the excess supply on the labor market) and sociological and political reasons (the growing resistance in Western countries to immigration flows), a sharp increase in immigration flows seems very unlikely in the years to come. Therefore, Western populations will evolve mostly according to fertility and mortality patterns.

The aging of Western countries' populations seems a given fact. This does not mean, of course, that the fertility rate will not rise again in the future, but this is a phenomenon that is hard to predict, hard to achieve, and hard to date with any precision.

\section{The mounting pressures on transfer mechanisms between age groups}

Due to the aging of populations, pay-as-you-go mechanisms such as social security and health care will experience difficulties. The number of potential contributors will grow less 


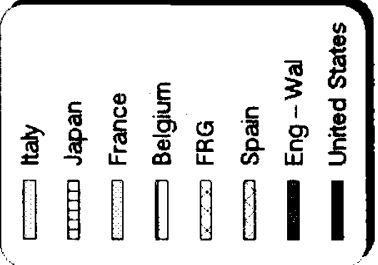

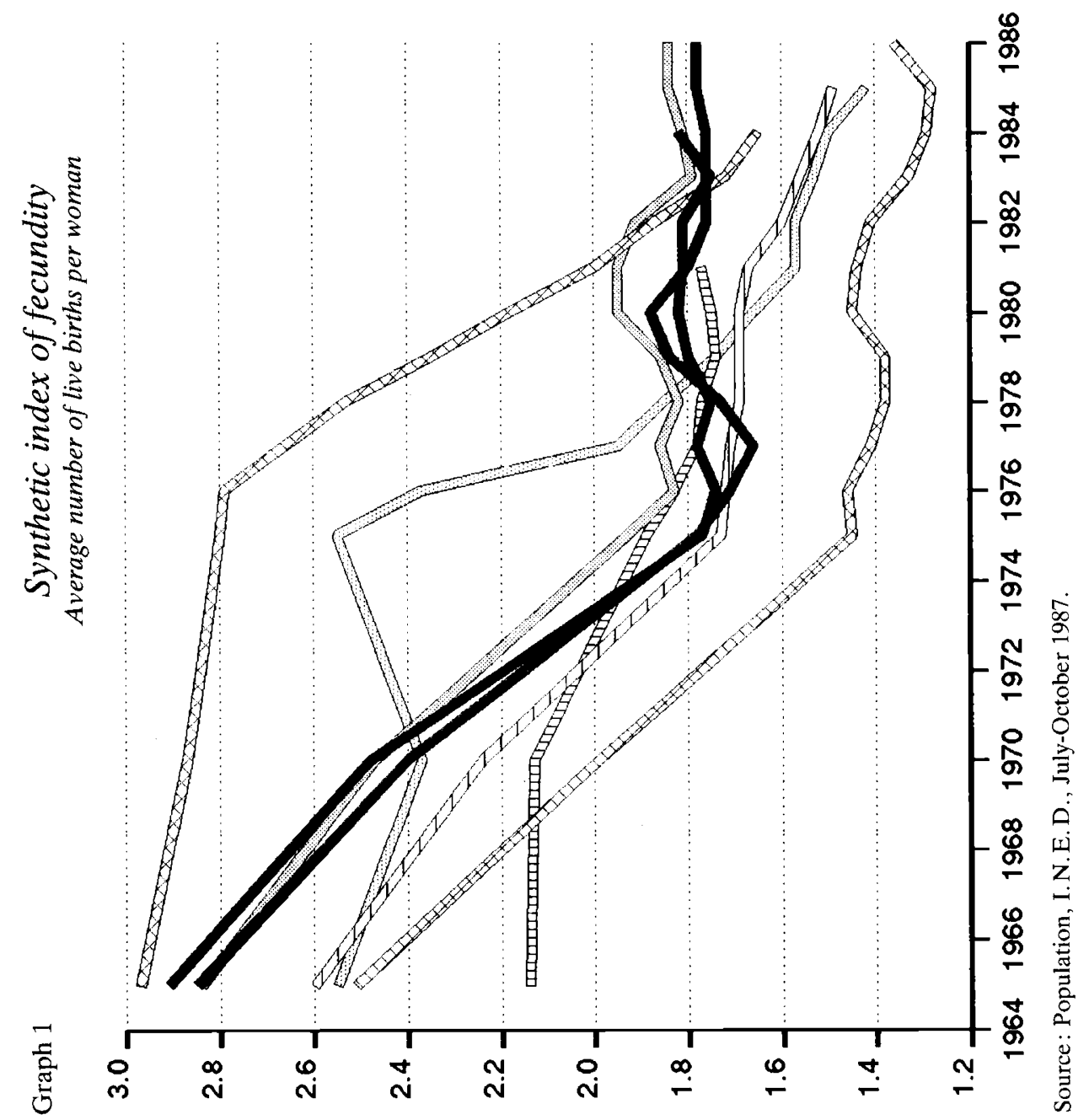


rapidly than the number of potential beneficiaries, putting these schemes under heavy pressures.

To overcome these foreseeable difficulties, a number of so-called solutions have been proposed: contributions could be raised, benefits could be lowered, the retirement age could be raised, etc. Some people advocate an increase in personal savings, others consider that pay-as-you-go systems are perfectly viable, still others firmly believe in funded pension schemes. There are even those who suggest that retirement itself - and thus retirement schemes - could eventually be phased out.

There are indeed three and only three possible variables upon which to act with respect to a pay-as-you-go system in an era of aging populations : contribution levels, benefit levels, and retirement age. What appears clearly is that the "internal rate of return" of these schemes will be lower for young cohorts entering the system than for cohorts enjoying retirement today or in the near future. In other words, for a given stream of contributions paid to the system during the active part of the life cycle, the benefits will be, other things being equal, lower (or, for a given stream of benefits, the stream of prior contributions will have to be higher or of longer duration).

It has been suggested by some that if we raise contribution rates in the future, the internal rate of return of social security schemes will not decrease. This, of course, is wrong. It will only postpone for a while the decrease of this "rate of return", which will itself affect later cohorts even more dramatically. At any rate, the existing pas-as-you-go schemes will be less profitable in the future than they have been in the past and than they are today.

Let us be forthright : the problem is as easy to present theoretically as it is difficult to solve practically. In the long term, the steady state equilibrium of the old-age social security system associated with a permanent regime of low fertility has nothing to do with today's equilibrium. For each country, that is to say for each system, it is possible to compute the possible long term steady state equilibria.

In Graph 2, we show a theoretical long-term equilibrium for a given social security system. The figure must be read as follows: if we assume that the level of contributions relative to GDP and the relative value of benefits are to be maintained at their current levels, the retirement age must be increased by, say, 13 years (point $A$ ). If the current retirement ages and the current level of contributions are to be maintained, the relative value of benefits must be decreased by 50 percent (point B). All combinations of these three parameters are possible. The problem is therefore one of determining the optimal mix of these three policy options. For this, one must first define the criteria which come into play when choosing this optimal policy mix. Then comes the question of whether the chosen solution is feasible, in other words if its implementation is not an almost impossible task.

Let us first stress the point that it is better to announce the chosen mix as early as possible rather than to wait. Rules governing the adaptation must be announced, and of course followed up and implemented, so as to attenuate the current lack of trust in the future of old age security schemes. If the decision is taken to lower benefits, the behavioral response of households (presumably an increase of personal savings) is very likely to be different from their reaction to an increase of contributions or an increase in mean retirement ages. For households to prepare optimally for the diminishing rate of return of the pay-as-you-go social security scheme, they must know, for instance, as soon as possible - expectations do play a crucial role - whether they have to save more today or work longer tomorrow. 
Graph 2

Conditions for long-term equilibrium between contributions, benefits and retirement age

Contributions global rate

(Benefits/GDP)

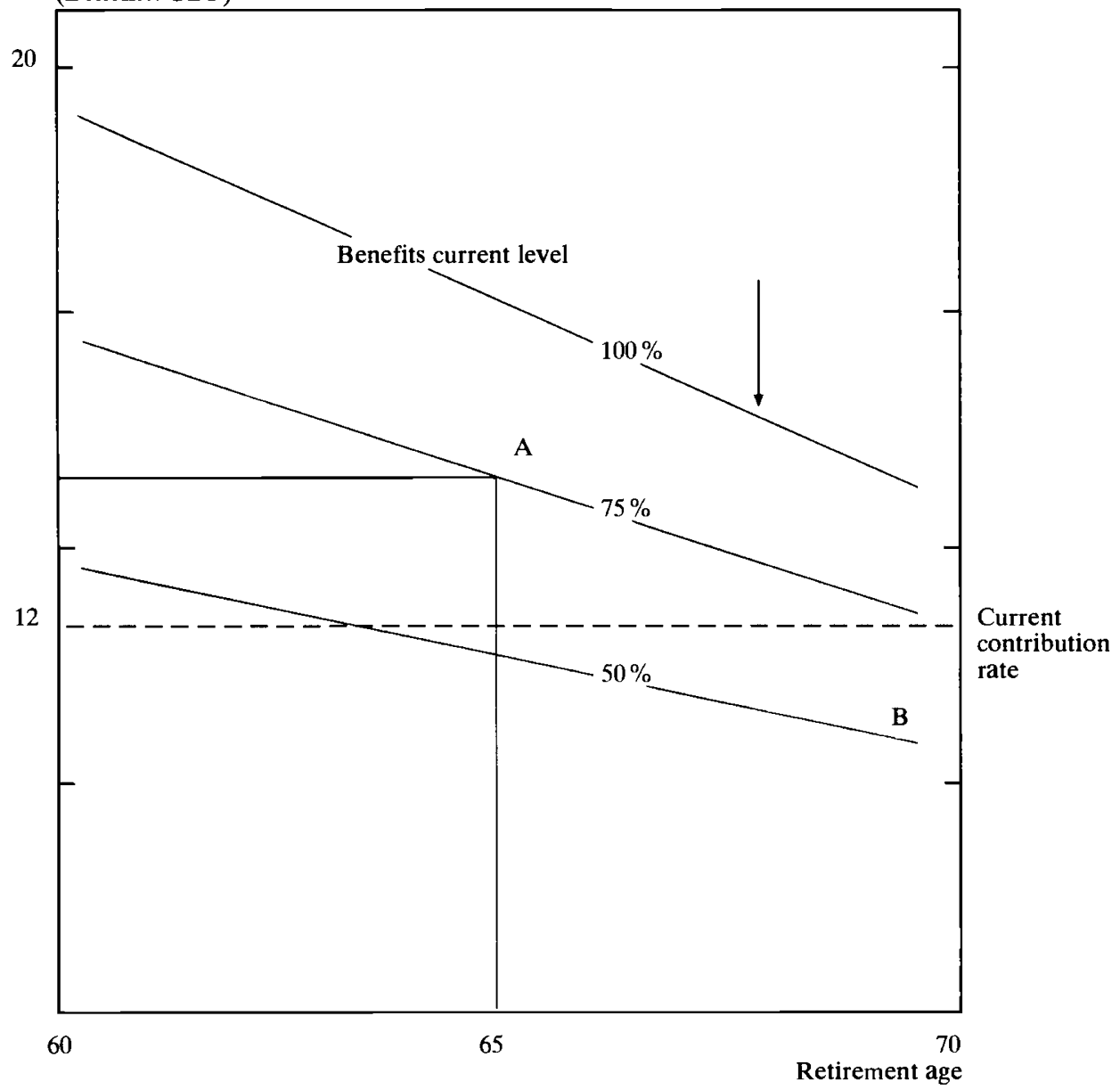

If they choose to save more today, they are in fact transferring purchasing power from one period to the next. They will accumulate wealth in the first period and then decumulate wealth by selling assets, as stated by the life cycle theory of saving. If they choose to work longer tomorrow, they might not need to save much more, but they will have to anticipate a longer career, and therefore a different lifetime profile of resources. The allocation of time over the life cycle is, of course, directly linked with the allocation of resources. 
To adapt to the inevitable decrease of the rate of return of pay-as-you-go schemes in a way which avoids shifting the burden onto the shoulders of the next generations (through a constant increase of contributions or of taxes) and which also averts a sharp decrease of the standard of living in old age (through an uncompensated decline in benefits), it would seem there is no way other than to save more today or to work longer tomorrow. But is this possible?

Two basic questions appear crucial in this respect : the first one is linked to the problem of the savings capacity of households - and to the functioning of the capital market; the second to the work ability of the aged - and to the functioning of the labor market.

\section{Saving more today}

As it is well known, a pay-as-you-go social security system may induce very large intergenerational transfers in the context of the worsening demographic ratios forecast for early next century. To avoid such an undesirable and, most likely, unsustainable shift of the burden of aging onto future generations, some observers have advocated that the third pillar of retirement - and the second pillar when it operates on a funded basis - should be promoted. In other words, the current active generations would try to transfer purchasing power to the next period by accumulating assets that they will be able to sell tomorrow in order to finance their consumption expenditures during their retirement period, or assets that will generate income (dividends, interests, rents...).

At first glance, an increase in today's saving would not change the future burden of the active population. Whether resources are transferred tomorrow to retirees via contributions or via capital income is irrelevant: "the quantity of soup to be transferred depends on the number of people around the table, not on the type of spoon used". That is to say, that if a lot of people are inactive tomorrow and relatively few are on the labor markets, then the true problem lies in the level of production and the respective shares devoted to the retired and to the active generations; whether this "burden" is placed on active generations through capital income (dividends, interest, rents...) or through the sale of retirees' assets at higher prices, or through contributions and taxes, would be of secondary importance (there would be intra-cohort distributional effects).

This oft-heard statement may be true in a static framework, but it is very misleading in a dynamic framework. Accumulating wealth through higher savings until the demographic implosion will increase the volume of "soup" to be transferred. The increase of savings, if the latter are wisely invested, should contribute to an increase in production. If we believe that part of the economic slump is due to a shortage of capital and investment, an increase of saving should exert a positive supply effect. The twist in the production function in favor of capital should last, and therefore a more active capital formation policy would lead to higher growth.

The quality of the saving devoted to long term retirement purposes is of special economic interest. This saving is contractual, stable, usually collectively managed (through pension funds, insurance companies, etc.), non inflationary, mostly oriented towards productive investments. It is a "superior quality" of saving compared, for instance, to bank or savings deposits. 
There can be no doubt that an increase in savings will contribute first, to greater equity between successive generations (it has the effect of sharing the burden of aging across many generations) and second, to economic efficiency (it has the effect of alleviating part of the total burden).

The true question is not whether to save more or not - because most people would agree on the positive economic effect of saving in the long term through a supply effect but whether it is possible to increase the level of aggregate savings via an increase of funded schemes (second pillar) or by way of households' initiatives (third pillar).

Let us recall that, according to available data, the level of wealth accumulation has declined since the mid-seventies in Europe as in North America (and this seems to be true also in Japan) (Graph 3). This is, of course, a worrisome development for those subscribing to the view that an increase in saving has positive effects on long term economic growth. It is precisely at a time when a higher accumulation is needed to prepare the future and to avoid a shift of the "old age burden" that we encounter a decline in the rate of savings.

When looking at the possibility of raising the personal savings rate, three questions must be addressed: (1) the possibility of acting on the aggregate household savings rate; (2) the substitutable or complementary nature of alternative household investments; and (3) the substitutability or complementarity of personal, corporate and government savings.

\section{(1) Is it possible to act on the level of the household savings rate?}

The different theories explaining household savings behavior more or less converge on the fact that income (whether it is a question of current, permanent, life cycle or intergenerational resources) plays the most important role in asset accumulation. The other variables, such as the prevailing interest rate, the current government deficit, the distribution of income, the composition of resources, taxation, etc. play a minor role in the household savings rate, if at all. These variables affect more deeply the structure of savings flows, but they seem rather weak in explaining the evolution of the global volume of savings.

At any rate, if the aim is to increase the household savings rate, policymakers should be prepared to increase the amount of their short- and medium-term resources. Will this induce a net increase of the level of aggregate national savings?

\section{(2) Are the savings of the different economic agents substitutable or complementary?}

The level of household savings should not be considered in isolation. Indeed, what is important is the global rate of savings of a nation that results from the saving or dissaving behavior of all the national economic agents. When we consider the rate of private saving the picture is slightly less gloomy than when we look only at household, or personal savings. It is true that in the last five years the rate of saving by firms has been on the rise: in most European countries, the current trend is an increase in business profits and in self-financing. The rate of corporate savings has been rising since the $1980 \mathrm{~s}$, as can be seen from national accounts, largely due to the fact that wage rate increases have been moderate. Even if corporate savings have counterbalanced the decline or stagnation of household savings, the overall rate of accumulation of industrialized countries remains inferior to the one that prevailed before the first oil crisis. 

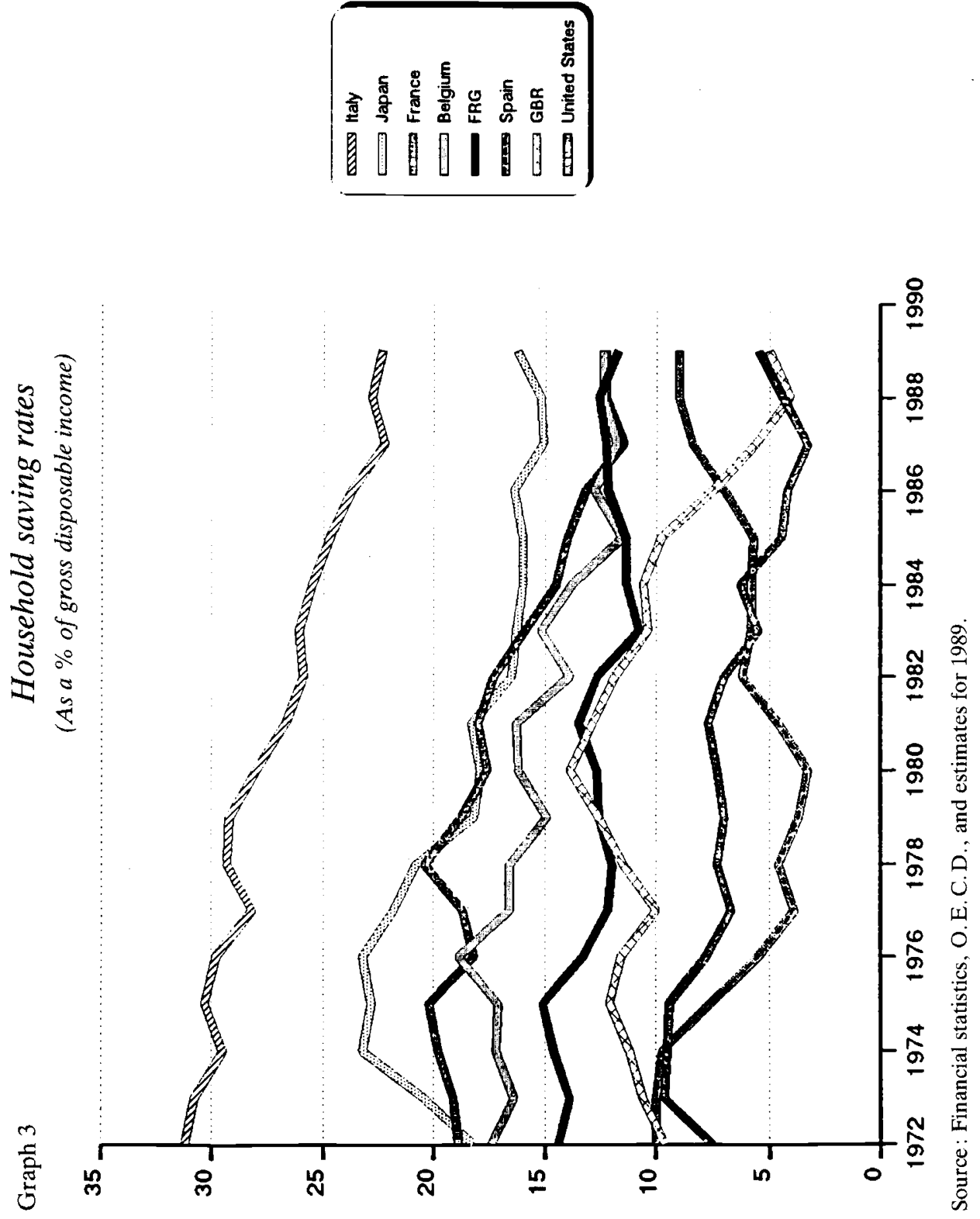
The stability of the private savings rate (household and corporate savings) has been first advocated by Denison (1958) and then by David and Scadding (1974). According to their ultra-rationality hypothesis, households are perfectly aware of what goes on in the business sector. In other words, there is no veil between the household and business sectors. The accumulation achieved at the firms' level is fully taken into account by households in their decisions to save out of their disposable income. The fact that accumulation is done at the household or corporate levels is not important, since firms belong to households anyway. Their growth will sooner or later be reflected in the value of households' portfolio. In this perspective, only the aggregate private savings rate matters. Even if the recent empirical evidence does not seem to indicate such a total stability of the private savings rate, it does indeed seem that there is a partial substitution between household and corporate savings. When we succeed in raising the rate of corporate savings, we must also somehow expect a decline in the rate of personal savings and vice versa, even if the decline is not on a one to one basis.

As regards the relationship between the private savings rate and the saving or dissaving behavior of the government sector, the theoretical answer is not quite clear. Certain observers consider that today's dissaving by government will be financed by higher taxes tomorrow. If households are anticipating this increase of taxes linked to the current deficit, they will increase their saving to avoid an undesired change in their intertemporal or intergenerational consumption plans (see Barro, 1984). If they are myopic and they do not anticipate these taxes, deficits could raise the overall rate of consumption and lower the national savings rate. Most empirical studies carried out to test the effects of government deficits on savings conclude that they are more likely to be associated with an increase of consumption than with an increase of savings. Therefore budget deficits would negatively affect private savings behavior.

Hence, raising the household saving rate will not be sufficient to transfer resources from today to tomorrow. It would be useless to increase the household savings rate if this were at the expense of business saving. The true objective is to increase the national savings rate, and in this respect controlling government dissaving (and pushing it to invest rather than to consume) appears as a top priority. One can only repeat that the goal is easy to define, but the means are more difficult to find.

Let us state clearly that we still know little as to why people actually save or not, just as we do not know why they choose to have children or not. The fact that, at the same time, they save little and have few children may well induce observers to think that the real key lies in the attitude of current generations vis-à-vis the future.

\section{(3) Are the different savings motives interdependent?}

The idea here is different from the one we just addressed. If households are given the incentive, notably through fiscal breaks, to save more for their retirement (as it is done in most industrialized countries), will this be likely to increase the level of household savings? The issue here is to know whether or not the savings behavior of households is "segmented".

Let us assume that households have three main objectives when saving: the first one only concerns short-term precautionary motives; the second one is aimed at supplementing resources upon retirement ; and the third one is related to the bequest motive. If these three objectives were relatively independent of each other, then an increase in the bequest 
motive, for instance, would not affect the short-term precautionary motives or the retirement financing (or life cycle) motive. In this case, if households were to participate more actively in the financing of their retirement period because they anticipated a decline in the relative value of public or private pensions, then they would save more, with no substitution taking place between the different savings flows. On the opposing side, one can argue that the savings motives are interdependent, and that households allocate a given level of savings between different investments.

According to both theoretical analysis and empirical evidence, it is clear that there is a limited substitutability between savings on one side and annuities on the other (Kessler and Tang, 1989). This is particularly true when capital markets are imperfect. When a household invests in an insurance policy leading to an annuity, there is indeed a limited substitution effect on its other investments. But other forms of saving appear more interdependent, and substitution effects are very likely. The growing awareness of the public to the future difficulties of social security schemes could in this respect induce them to invest more in long term assets or to increase their coverage by funded pension schemes, but this could be done at the expense of alternate types of investments.

The problem with the "savings solution" is well known: saving is an efficient way to prepare for future consumption needs if and only if asset accumulation allows a real transfer of purchasing power. If current working generations do engage themselves in an accumulation effort (enlarging principally the third pillar, but also the second pillar), it must be recalled that this solution assumes that the capital market functions well. A high inflation rate, a stock market crash, a decline in the value of real estate... may well ruin the efforts of households (as has been historically the case, calling for government implementation of social security schemes...).

To predict the future of household savings, and assess its contribution to the financing of the later stages of the life cycle, one therefore has to ask if the reversibility of observed trends is possible. Is the decline in saving by households the result of an "unfavorable environment" or does it reflect a "change in taste"? Let us point out that the same question can be raised concerning the decline in fertility.

\section{Working longer tomorrow?}

If a very sharp increase of the savings rate seems a difficult thing to predict, can one judge if it would be possible to postpone actual retirement ages? On this matter also the answer is not clear-cut.

The past trends are well known: in all industrialized countries, activity rates at later ages have sharply dropped, as can be seen in Graph 4. Current retirement ages average 62 years in most OECD countries. In industrialized countries, only a very small minority of persons participate in the labor market past the age of 65 . The decline of activity has affected even the 55-60 year age groups that have been the beneficiaries of early retirement programs introduced in almost all industrialized countries since the mid-seventies. Since life expectancies have risen in the meantime, the average length of retirement has been markedly increasing, representing between one fifth and one fourth of total lifetime (let us remark, however, that there are still inequalities in the duration of lifetime, and hence that the dispersion of retirement durations is still important). 

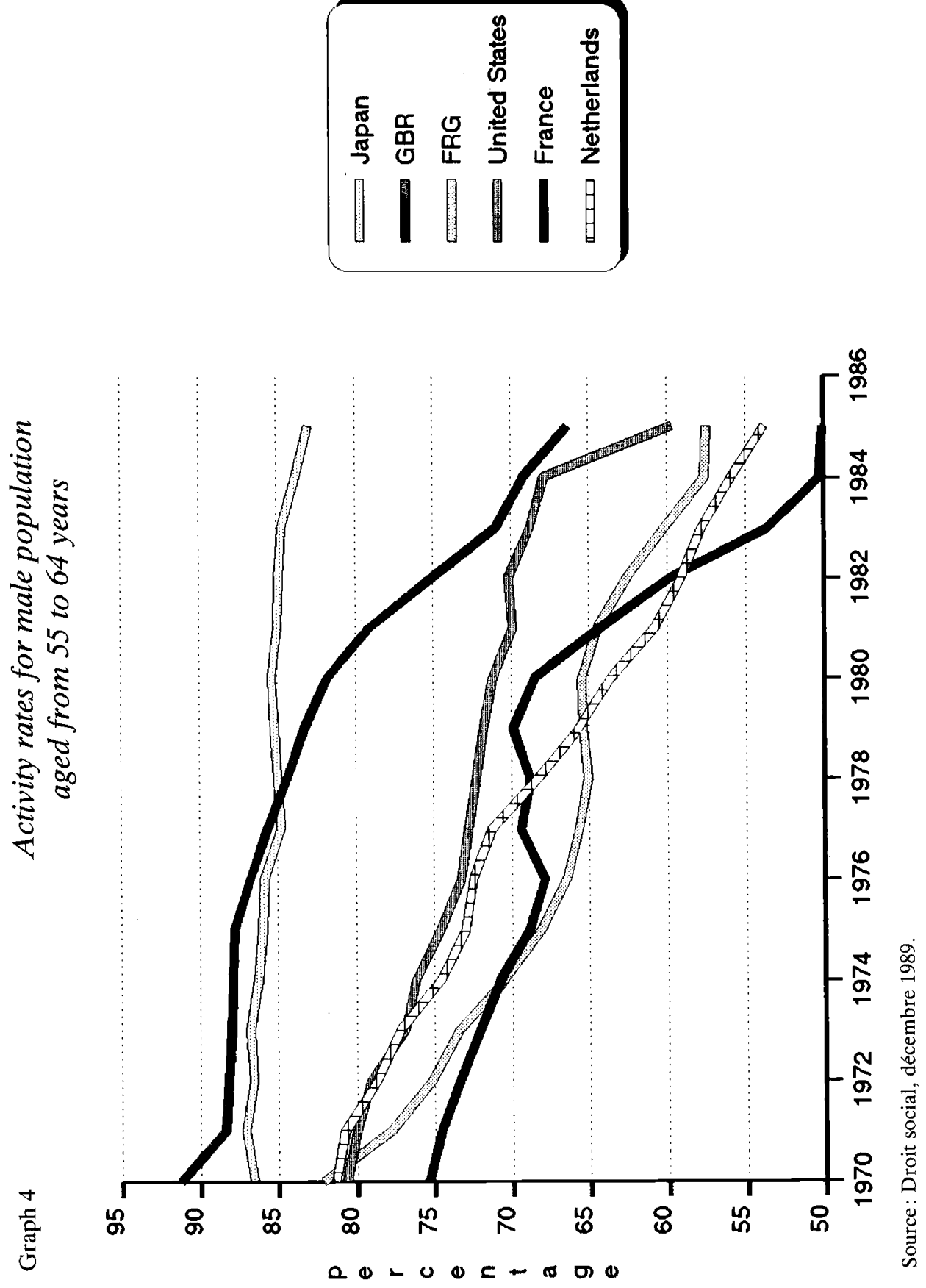
The main causes of this decline of activity rates among the aged are linked to the retirement-inducement effect of social security and private pension schemes (the labor-leisure choices of the aged have been distored by the clauses of the first two pillars of retirement), and the rise of unemployment affecting notably the aged.

To estimate the likelihood of an increase in the participation on the labor market of the aged, three main issues must be addressed.

\section{(1) How will the labor demand evolve?}

If the rise of unemployment has strongly induced - to say the least - aged workers to step off the labor market, we can equally consider that the decline of unemployment may exert the exact opposite effect. Alongside the numerous arguments that have been put forward to explain the rise of unemployment in developed countries, one must not forget the fact that the size of the cohorts (belonging to the baby boom generations) entering the labor force in the seventies was quite large. True, this fact taken alone cannot explain the large disequilibrium that has affected all industrialized countries, but there is no doubt that it has fuelled the number of unemployed.

When will the current excess supply on the labor market disappear? To answer this question, one has to distinguish between the short and the long term.

In the short and medium term, the schedule of the decline of unemployment will depend on the rate of growth of the economy and on the labor intensity of the new growth regime. It seems difficult to assess precisely the economic prospects for the industrialized countries, but certain recent trends seem to augur rather favorably (the enlargement of the world market to Eastern countries, the deepening of the EEC market, the progressive writing off of Third World debt...). Some of the most delicate adjustments have already been made, and there should be a higher and more balanced growth in the coming decade than in the past one. The relative size of the cohorts belonging to the baby bust era and entering the labor force in the coming years should decrease.

As far as the choice of techniques is concerned, it seems likely that the "employment content" of growth will remain low. The twist of the production function in favour of capital should continue, despite the fact that the relative cost of capital remains high compared to the cost of labor. For this reason, the improvement of the labor market situation will probably prove to be less rapid than was hoped for.

In the long term, the same demographic perspectives that are at the source of the difficulties of the social security systems should, by contrast, benefit the labor market. Available projections of the working population - based on population projections - indicate that there could be not only a relative but even an absolute decline of the working population in the period 2005-2020, when the baby boom generations will leave the labor market and the baby bust generations will all be on the labor market. A rise in the fertility rate should not radically modify the picture on this horizon.

Since the activity rates of women will not be able to increase in the future due to the fact that they have already reached high levels - close, if not identical, to men's - and that immigration seems to receive little public support, there might be some shortage of manpower, i. e. a labor market situation characterized possibly by excess demand. Such a situation would of course be a contributing factor to a possible reversal of the current trends in favour of early withdrawal from the labor force. 


\section{(2) How will the labor supply of aged workers evolve in the future?}

The labor force participation of aged persons depends, partially at least, upon their own intertemporal choices and decisions. One can assume that people tend to make laborleisure arbitrages over their whole life cycle, deciding jointly on the global allocation of their time and of their resources over their entire existence. When allocating their time over their existence, for instance, individuals take into account the stream of their income (this plays a particularly important role when capital markets are imperfect), their potential productivity profile, their subjective life expectancy, their current and future health status, the different social security and tax provisions, the arduous nature of one's work, its intellectual or manual characteristics, etc.

A priori, individuals could choose from among a large number of ways to allocate their time in maximising their intertemporal utility. Fields and Mitchell, (1984) have proposed six types of alternative retirement patterns (see Graph 5 , where $L_{t}$ is the number of hours worked and $T$ is the total available work time). Graph 5 illustrates six types of profiles: (1) retirement at age $R$; (2) retirement as soon as possible; (3) never retire: (4) intermittent work patterns; (5) part-time work, smoothly declining; and (6) part-time work with an irregular pattern. In reality, most of the observed profiles follow the first and second cases, in other words, complete cessation of activity at a given age, or full retirement as soon as it is possible.

There are, of course, numerous legal or contractual constraints which incite people to adopt such a profile rather than working part-time past a given age. But even in the absence of such "constraints", in the absence of social security and pension schemes, there is good reason to believe that people would still adopt such behaviour. Individuals are incited to work when it is most profitable; and, a priori, the latter part of the life cycle may not be the period of life when this condition is met (see below). The relative value of leisure is highest when the remaining time to live is limited. People are usually able to accumulate assets and acquire durables in the earlier part of their lifetime so that they may feel more secure to leave the labor market. But there is also the question of tastes and, according to survey results, most individuals declare they are satisfied by the way they have retired. The actual constraints would be of a second order: the gap between the actual and the desired patterns of retirement would be limited. If this were the case, the sharp decline of participation in the labor force by the elderly would not only reflect the rise of unemployment or the increase of social security and pension coverage but also a pure "labor supply effect", i.e. an increasing number of aged persons would prefer to retire early rather than late, would prefer to cease all activity than work part-time or intermittently.

If this were the case, the possible reversal of the observed decline in the labor force participation of the aged could notably come from a change of tastes, through what is called a "vintage effect", with tomorrow's generations choosing to retire later in their life cycle than today's generations. But as with fertility and savings behaviour, labor supply behaviour is hard to predict.

\section{(3) How will the long-term wage earner/firms relationship evolve?}

Let us turn now to the labor demand side and examine the long-term wage earner/firms relationship. The decline of activity rates among the aged could be reversed if, at the microeconomic level, a certain flexibility was again introduced in the way labor contracts function. 
Graph 5

Alternative retirement patterns

Fraction of

time worked

a. Retirement at $R$

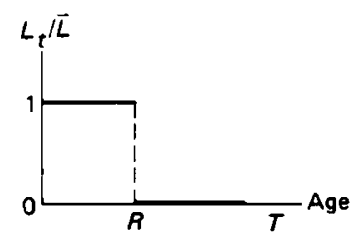

b. Retire as soon as possible

c. Never retire

$L_{t} / \bar{L}$

b. Retire as soon as possible

d. Intermittent work

e. Part-time work, smoothly declining

f. Part-time work, irregular pattern
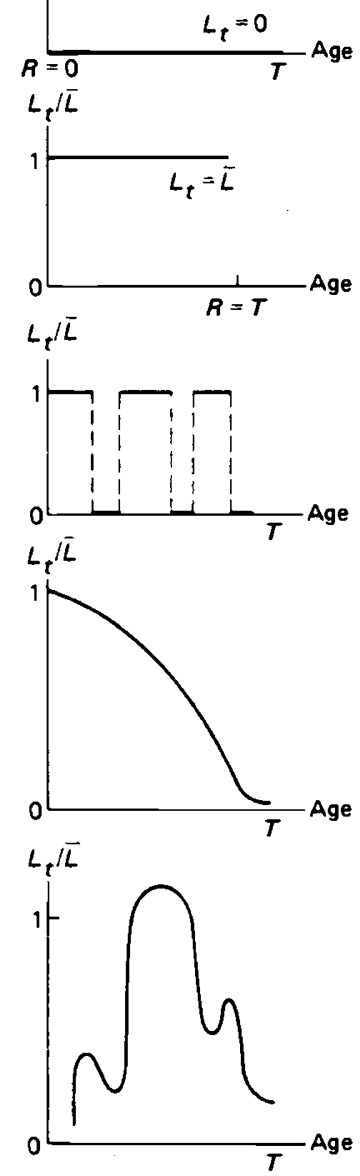

Source : Fields and Mitchell (1984). 
Many people have advocated a change in the process of retirement, which does appear partially constrained. Some wage earners are somehow forced to quit the labor market at a given age, even if they wish to go on working. They are sometimes put aside even if they are still productive. The social pressure in favour of early retirement is very strong, and both the corporate and labor unions agree, at least implicitly, that in case of problems, be they in a given sector, industry or firm, the aged are the first to be pushed out of the labor market.

Recent research has shown that the way labor contracts end is directly linked to how they operate throughout the worker's lifetime. To understand what happens at the end of the life cycle, one has to consider what happens at the beginning and in the middle of the life cycle. Both pension schemes and retirement patterns are linked to the nature of the long term ties linking an employee to his employer. The basic message of the research done during the last turbulent decade is that "a person's spot wage has little to do with his spot productivity but rather is an instrument of a complex insurance or deferred compensation scheme" (Cf. Hutchens, 1989, p. 49).

The basic idea of this line of research can be illustrated as follows (Graph 6) : let us assume a constant level of productivity $P_{t}$ throughout the life cycle. To assume a more realistic concave productivity profile would not change the message. In most cases, the wage profile $W_{t}$ increases throughout one's working lifetime until retirement. Until the age $t^{\prime}$, the employee accepts to be paid at a wage lower than his productivity, but under the implicit promise that he will be paid above his productivity during the second phase of his career, until $t$ ". This compensation package is efficient: the turnover is reduced, to the common advantage of the employer and the employee, and it notably reduces shirking. ${ }^{1}$

Is this relationship likely to evolve in the future? Our contention is that the "internal social security or pension scheme" (the implicit transfer scheme between aged workers in the second part of their career and young workers entering the labor force) will be put under very heavy pressure. In fact, the type of transfer mechanism just described is very efficient when there are lots of young employees and few aged employees. This mechanism cannot function properly when manpower, as a whole, ages. In fact, if there are more people in the second stage of their career than people in the first stage, the transfer mechanism cannot even operate. All seniority rules are indeed difficult to maintain in an era of aging manpower.

These demographic developments - the aging of the baby boom generations - will first affect manpower within the firms and thus contribute to the disruption of the existing longterm relationship between employers and employees. In effect, it is these very same generations - that will pose a problem to social security and pension schemes starting in the years 2005-2010 - which will also, beforehand, disrupt the age pyramid within the firms. There is a strong chance that the long-term relationship characterized by seniority rules, a defined income profile, a fixed retirement age, low turnover, and the implicit rule by which the aged are the first to go in case of difficulties may not last through the next fifteen years. We shall see more people working later tomorrow if the current relationship evolves, notably (1989).

${ }^{1}$ For a thorough overview of this compensation package, see Hutchens (1989) and Carmichael 
towards more flexibility, whereby the gap between spot productivity and spot wage is narrower than it is today. In order to assess whether people effectively do work later tomorrow and retire differently, one should be attentive to today's evolution of the implicit and explicit contracts between young wage earners and firms.

\section{Graph 6}

\section{Productivity and wage profile over the life cycle}

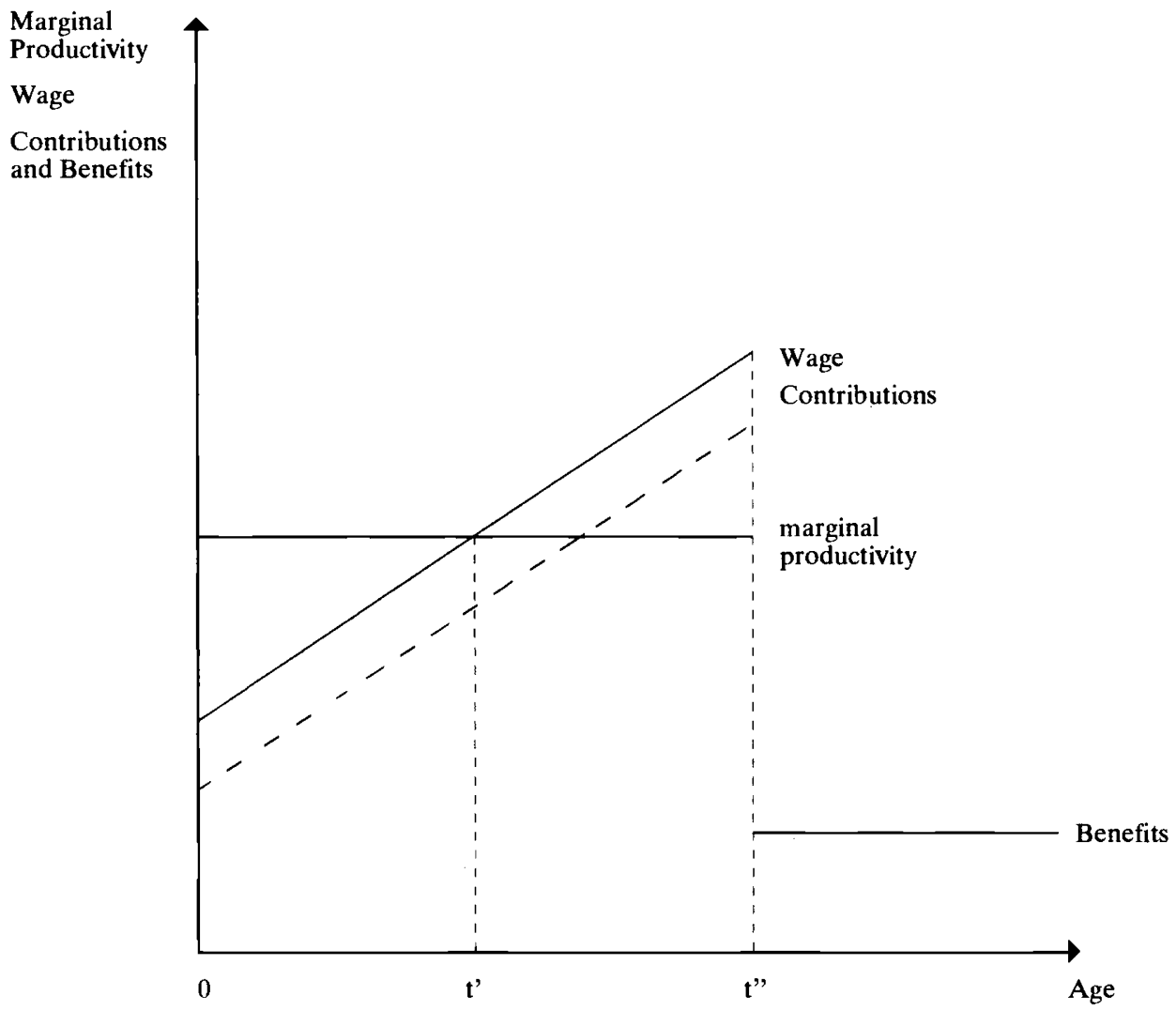

\section{Conclusion}

Four major phenomena have taken place during the last twenty years: the decline in fertility rates, the decline and stagnation of household savings rates, the decline in the participation rate of the aged in the labor force and the increase of social security and health expenditures. The combination of these four trends is explosive. All the transfer 
mechanisms introduced since the end of the second World War and aimed at organising the sharing of production between different age groups, will be put under very heavy pressure. This will primarily affect old age social security schemes functioning on the pay-as-you-go principle.

The solutions are not many: they may entail increasing fertility rates, household savings rates or the activity rates of the aged. Social sciences seem a little puzzled by the three phenomena. One has to accept the fact that, today, we do not know exactly why people actually have children or not, save or not, work or not. These three trends, the combination of which could be explosive, could well indicate a general change in tastes from one generation to the next. In this case, we would be facing what is labelled a vintage effect. But this could be the result of an unfavourable economic and social environment, in which case the priority would lie in the definition and implementation of active policies to restore an environment that is less potentially explosive than the one we see in industrialized countries and more favourable to long-term decisions, leading thus to less myopic behavior.

\section{REFERENCES}

BARRO, J.R., (1984), “Are Government Bonds Net Wealth?”, Journal of Political Economy, 82, 6, 1095-1117.

CARMICHAEL, L., (1989), "Self Enforcing Contracts, Shirking and Life Cycle Incentives", The Journal of Economic Perspectives, Vol. 3, No 4, Fall 65-86.

DAVID, P.A. and SCADDING, J.L., (1974), "Private Savings, Ultrarationality Aggregation, and 'Denison's Law'”, Journal of Political Economy, 82, 2, Part I, 225-249.

DENISON, E.F., (1958), "A note on Private Saving", Review of Economics and Statistics, 40, 3, 261-267.

FIELDS, G.S. and MITCHEL, O.S., (1984), Retirement, Pensions and Social Security, The MIT Press, Cambridge, Mass.

HUTCHENS, R. M., (1989), "Seniority, Wages and Productivity: A Turbulent Decade", Journal of Economic Perspectives, Fall, Vol. 3, № 4, 49-64.

KESSLER, D., (1988), "The Four Pillars of Retirement", The Geneva Papers on Risk and Insurance", Vol. 13, No 49, October, 342-350.

KESSLER, D., (1989), "But Why is There Social Security?", in Workers versus Pensioners: Intergenerational Justice in an Aging World, P. Johnson, C. Conrad, D. Thompson, Eds., Manchester, Manchester University Press, 80-90.

KESSLER, D., (1990), Les quatre piliers de la retraite, Rapport pour l'Association de Genève, Mars, mimeo.

KESSLER, D. and TANG, L., (1989), "Rente viagère ou capital ?", Paper presented to the 16th Seminar of the European Group of Risk and Insurance Economists, Paris, September.

LAZEAR, E. P., (1979), "Why is There Mandatory Retirement?", Journal of Political Economy, December, Vol. 87, 1261-1284. 